\title{
Commentary: Avoiding danger-Addressing the specter of coronary obstruction during transcatheter aortic valve replacement
}

\author{
Amar Krishnaswamy, MD, ${ }^{\mathrm{a}}$ Samir R. Kapadia, MD, ${ }^{\mathrm{a}}$ and Rakesh Suri, MD, DPhil ${ }^{\mathrm{b}, \mathrm{c}}$
}

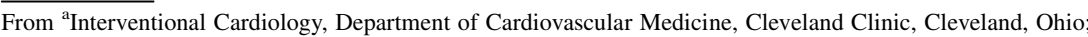
and ${ }^{b}$ Department of Thoracic and Cardiovascular Surgery, Cleveland Clinic Abu Dhabi, Abu Dhabi, UAE, and ${ }^{\mathrm{c}}$ Cleveland Clinic Foundation, Cleveland, Ohio.

Disclosures: Authors have nothing to disclose with regard to commercial support.

Received for publication May 7, 2019; accepted for publication May 8, 2019; available ahead of print June 27, 2019.

Address for reprints: Rakesh Suri, MD, DPhil, Department of Thoracic and Cardiovascular Surgery, Cleveland Clinic, 9500 Euclid Ave, J4-1, Cleveland, OH 44195 (E-mail: surir@ccf.org).

J Thorac Cardiovasc Surg 2020;159:839-41

$0022-5223 / \$ 36.00$

Crown Copyright (C) 2019 Published by Elsevier Inc. on behalf of The American Association for Thoracic Surgery https://doi.org/10.1016/j.jtcvs.2019.05.006
}

In the current issue of the Journal, Heitkemper and colleagues ${ }^{1}$ have aimed to provide the heart team with a screening tool to assess coronary obstruction risk during transcatheter aortic valve replacement (TAVR). They selected 28 patients they believed might have been excluded from TAVR because of "high obstruction risk" on the basis of low coronary height or small sinus of Valsalva diameter. They then performed computed tomographic analysis to compare the 23 of these patients who underwent TAVR uneventfully with the 5 of these patients who either had coronary obstruction (1 patient) or had cardiac surgery (2 patients) or did not undergo any procedure (2 patients) because of concern for coronary obstruction. Ultimately, Heitkemper and colleagues ${ }^{1}$ concluded that a ratio between the distance from the cusp to the coronary ostium and the coronary artery diameter (as a marker of the degree of coronary lumen obstruction) had a 100\% sensitivity and $96 \%$ specificity for predicting coronary obstruction.

Preprocedural evaluation of the aortic root anatomy to assess the risk of coronary obstruction during TAVR is essential, because this feared complication may occur in as many as $0.2 \%$ to $0.4 \%$ of patients and is associated with a very high mortality. ${ }^{2}$ Although Heitkemper and colleagues ${ }^{1}$ are to be commended for their intricate computed tomographic modeling and inquisitive analysis, drawing generalizable conclusions from the data of 23 patients who underwent TAVR without obstruction compared with only 5 patients who did not (only 1 of whom actually had coronary obstruction) may be somewhat of a reach. The intended rationale for the study is to understand which patients with "high obstruction risk" may not have been treated because of sinus of Valsalva diameter or coronary height. After reviewing the article's Table 1, however, we politely suggest that most experienced operators would have treated most (if not all) of these patients. Taking into consideration the low versus high obstruction risk features

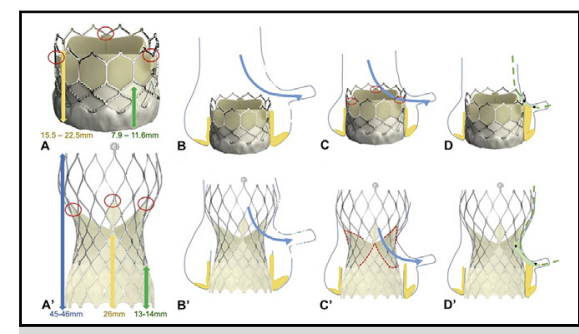

Transcatheter aortic valve replacement and coronary protection technique.

Central Message

Assessing risk of coronary obstruction with TAVR is imperative. Equally important and addressed by this editorial are methods to protect against obstruction in those patients who still require TAVR.

See Article page 829 .

detailed in our own Table 1 in the context of intended valve size, almost all the patients included in the series of Heitkemper and colleagues ${ }^{1}$ would have been treated without significant concern for coronary obstruction.

Although patients at high risk ("threatened obstruction") can be safely and effectively treated with various approaches along with different valve types (Figure 1), it is of course important to remain cautious about the specter

TABLE 1. Factors to consider in assessing coronary obstruction risk during transcatheter aortic valve replacement

\begin{tabular}{|c|c|c|}
\hline & Low obstruction risk & $\begin{array}{c}\text { High obstruction } \\
\text { risk }\end{array}$ \\
\hline Coronary height & $>10 \mathrm{~mm}$ from annulus & $<10 \mathrm{~mm}$ from annulus \\
\hline Coronary origin & Edge of cusp & Middle of cusp \\
\hline Leaflet length & $<$ Coronary height & $>$ Coronary height \\
\hline Leaflet calcification & Bulky at leaflet base & Bulky at leaflet tip \\
\hline Sinus dimension & $>$ Valve size & $\approx$ Valve size \\
\hline Sinotubular junction & $>$ Valve size & $\approx$ Valve size \\
\hline $\begin{array}{l}\text { Height of sinotubular } \\
\text { junction }\end{array}$ & $\begin{array}{l}\text { Higher than coronary } \\
\text { leaflets or prosthetic } \\
\text { frame }\end{array}$ & $\begin{array}{l}\text { Lower than coronary } \\
\text { leaflets or prosthetic } \\
\text { frame }\end{array}$ \\
\hline $\begin{array}{l}\text { Prosthetic leaflet } \\
\text { structure }\end{array}$ & $\begin{array}{l}\text { Within the surgical } \\
\text { frame }\end{array}$ & $\begin{array}{l}\text { External to the } \\
\text { surgical frame }\end{array}$ \\
\hline
\end{tabular}




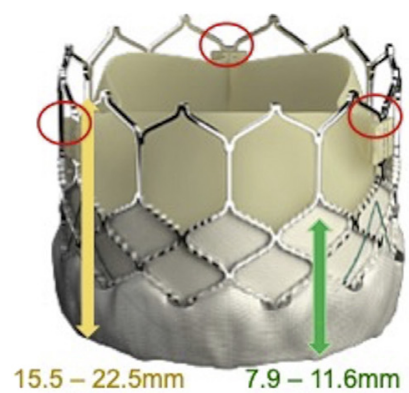

A

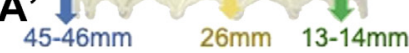

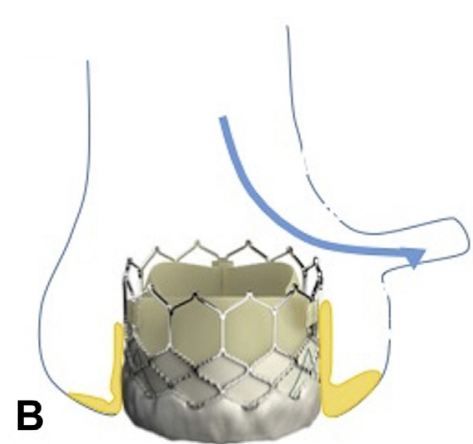
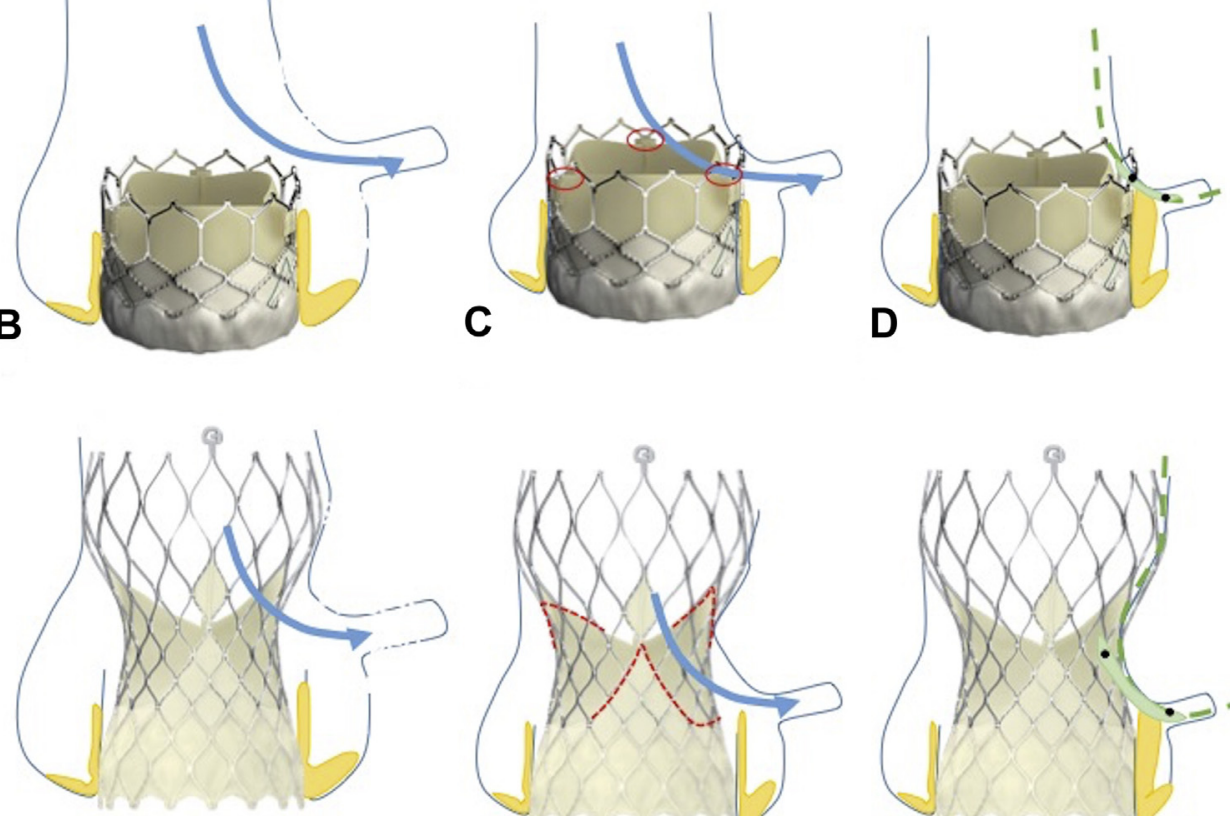

$B^{\prime}$
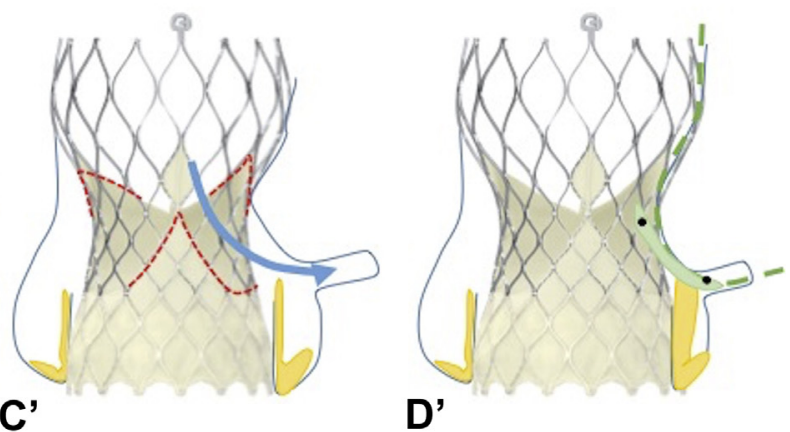

FIGURE 1. Transcatheter aortic valve replacement and coronary protection technique. A and A', SAPIEN 3 (Edwards Lifesciences Corporation, Irvine, Calif) and Evolut R (Medtronic, Minneapolis, Minn) valves. Note that height of the frame (blue arrow), height of the outer covering (green arrow), and commissural height from bottom of valve (yellow arrow) are different for these valves and for different sizes. B and $\mathrm{B}^{\prime}$, Low-risk anatomy with large sinuses and high takeoff of the left main coronary artery. $\mathrm{C}$ and $\mathrm{C}^{\prime}$, Lower sinotubular junction height but shorter leaflets and good coronary height. Coronary occlusion is not likely to be an issue here, but access can be difficult depending on commissural alignment (red circles, corresponding to panels $\mathrm{A}$ and $\mathrm{A}^{\prime}$ ). $\mathrm{D}$ and $\mathrm{D}^{\prime}$, High-risk anatomy (bulky leaflet calcification, long leaflet, small sinuses, and low left main coronary artery origin) with balloon or stent protection (as shown, the "snorkel" length can depend on the type of valve used; placement of the stent "through" the transcatheter aortic valve replacement prosthesis frame should be considered if the patient is in stable conditions). A BASILICA (bioprosthetic or native aortic scallop intentional laceration to prevent coronary artery obstruction) procedure to slice the leaflet can be a consideration.

of coronary obstruction during all cases. We reported the first successful rescue of a patient after acute coronary occlusion on TAVR deployment in our early experience, and we suggested several technical maneuvers to rescue a patient from this complication. ${ }^{3}$ Prevention, however, is generally the best approach. One option is to prewire the threatened coronary artery and advance a stent beyond the coronary ostium before valve implantation. If obstruction occurs, the device can be pulled back and inflated to restore flow. For the most part, this "stent snorkel" technique involves placing the proximal part of the stent into the ascending aorta. As the stent required is often much longer when a tall-framed self-expanding valve is used, and reaccess to the ostium of this stent is more complicated, we prefer the use of a shorter balloon-expandable valve in these cases.

If the sinotubular junction is high and there is room to advance a stent or balloon above the valve frame into the coronary artery, a balloon is often adequate to protect the coronary artery, and a stent can be advanced thereafter if necessary. If there is concern about closure at the level of the sinotubular junction, it is often easier to protect with a stent, because it may not be possible to advance a stent after valve deployment. In cases in which stenting is necessary, the technique of placing the stent can be nuanced. After valve deployment, if there is partial obstruction but the patient is in stable condition and the stent or balloon can be removed from the coronary artery, consideration should be given to reengaging the coronary ostium with another guide through the valve stent strut to provide a more coaxial stent and (theoretically) easier reaccess, because the stent can be placed immediately adjacent to the valve frame rather than beside or behind the valve frame (this latter placement is shown in Figure 1).

Another option is that of intentional coronary leaflet laceration before valve implantation. Although this procedure, which has been dubbed BASILICA (bioprosthetic or native aortic scallop intentional laceration to prevent coronary artery obstruction), ${ }^{4}$ has been used more frequently for valve-in-valve procedures, it has been successfully 
performed for native aortic valve leaflets as well. In brief, the technique uses electrocautery to "slice" the threatening leaflet and allow it to splay aside, rather than toward the coronary ostium.

One other important point to consider is the possibility of "late" coronary obstruction. ${ }^{5}$ Often, this is due to partial obstruction that is not recognized at the time of the procedure. Many operators perform TAVR without routine completion aortography, and there is thus no contrast visualization of the coronary arteries at the end of the procedure. Especially in patients with high obstruction risk, selective angiography in addition to nonselective aortography should be considered at the end of the procedure.

Two special circumstances that are not addressed by this study should also be considered: bicuspid TAVR and valvein-valve TAVR. Both these anatomic circumstances are associated with higher coronary obstruction rates than are seen with native valve TAVR. ${ }^{6,7}$ In bicuspid TAVR, the leaflet length and raphe pushing the TAVR valve eccentrically can play a role in coronary occlusion. For valve-in-valve TAVR, the distance of the surgical valve struts from the coronary ostia is an important predictor, in addition to the anatomy of the valve (ie, leaflets inside vs outside the valve frame) and angulation of valve implantation. In contrast to native valve TAVR, the right coronary artery is involved more often in these situations.

An important question that is not addressed in the current study of Heitkemper and colleagues ${ }^{1}$ is the issue of future coronary access. Reengaging the coronary arteries for diagnostic or interventional procedures may be hampered by the TAVR prosthesis itself. In patients receiving an Edwards SAPIEN valve (Edwards Lifesciences Corporation, Irvine, Calif), difficulty with coronary reaccess is relatively rare, because the valve frame is generally confined to the aortic root, and access to the coronary arteries is gained either through the superior set of struts or from above the valve. Because the Medtronic CoreValve (Medtronic, Minneapolis, Minn) series has a tall frame that extends into the ascending aorta, cannulation of the coronary arteries may be impeded by the stent struts themselves. In patients with a narrow ascending aorta or a short aortic root, careful consideration should be made with respect to the 26-mm commissure height of this valve, which could make coronary reaccess impossible if the valve post and attached leaflet tissue are situated in front of the coronary artery and cannot be navigated around because of the described anatomic features (Figure 1). ${ }^{8}$

A final concern is that of coronary access in patients who require placement of a TAVR within a TAVR. Although there are a number of contemporary analyses demonstrating that TAVR and SAVR prosthetics have similar longevity, applying these valves to younger patients will undoubtedly lead to a need for TAVR within TAVR in the future. ${ }^{9}$ If the TAVR valve leaflets reach the sinotubular junction, as is more commonly the case for the Medtronic CoreValve series, a second TAVR will essentially result in the first valve leaflets creating a "tube" from the left ventricular outflow tract to the ascending aorta. Especially for patients with a narrow sinotubular junction, not only would this complicate coronary reaccess, it could also isolate the sinuses and jeopardize coronary flow. Current valve choice should therefore take this factor into consideration as well.

In summary, there are multiple factors to consider when assessing a given patient's anatomic risk for coronary obstruction with TAVR. Similarly, there are different approaches that can be useful in mitigating the risk of acute obstruction, including prewiring as well as understanding valve choices. Further, especially in younger patients or those who have preestablished coronary artery disease and are likely to require coronary reaccess, keeping future needs in mind is also important in planning the present-day procedure.

\section{References}

1. Heitkemper M, Hatoum H, Azimian A, Yeats B, Dollery J, Whitson B, et al Modeling risk of coronary obstruction during transcatheter aortic valve replacement. J Thorac Cardiovasc Surg. 2020;159:829-38.e3.

2. Ribeiro HB, Webb JG, Makkar RR, Cohen MG, Kapadia SR, Kodali S, et al. Predictive factors, management, and clinical outcomes of coronary obstruction following transcatheter aortic valve implantation: insights from a large multicenter registry. J Am Coll Cardiol. 2013;62:1552-62.

3. Kapadia SR, Svensson L, Tuzcu EM. Successful percutaneous management of left main trunk occlusion during percutaneous aortic valve replacement. Catheter Cardiovasc Interv. 2009;73:966-72.

4. Khan JM, Dvir D, Greenbaum AB, Babaliaros VC, Rogers T, Aldea G, et al. Transcatheter laceration of aortic leaflets to prevent coronary obstruction during transcatheter aortic valve replacement: concept to first-in-human. JACC Cardiovasc Interv. 2018;11:677-89.

5. Jabbour RJ, Tanaka A, Finkelstein A, Mack M, Tamburino C, Van Mieghem N et al. Delayed coronary obstruction after transcatheter aortic valve replacement. J Am Coll Cardiol. 2018;71:1513-24.

6. Yoon SH, Bleiziffer S, De Backer O, Delgado V, Arai T, Ziegelmueller J, et al Outcomes in transcatheter aortic valve replacement for bicuspid versus tricuspid aortic valve stenosis. J Am Coll Cardiol. 2017;69:2579-89.

7. Ribeiro HB, Rodés-Cabau J, Blanke P, Leipsic J, Kwan Park J, Bapat V, et al. Incidence, predictors, and clinical outcomes of coronary obstruction following transcatheter aortic valve replacement for degenerative bioprosthetic surgical valves: insights from the VIVID registry. Eur Heart J. 2018;39:687-95.

8. Yudi MB, Sharma SK, Tang GHL, Kini A. Coronary angiography and percutaneous coronary intervention after transcatheter aortic valve replacement. J Am Coll Cardiol. 2018;71:1360-78.

9. Søndergaard L, Ihlemann N, Capodanno D, Jørgensen TH, Nissen H, Kjeldsen BJ et al. Durability of transcatheter and surgical bioprosthetic aortic valves in patients at lower surgical risk. J Am Coll Cardiol. 2019;73:546-53. 